\title{
The Role of School Leaders in Teacher Leadership Development
}

\author{
Marjorie C. Ringler \\ East Carolina University \\ Debra O'Neal \\ East Carolina University \\ Jana Rawls \\ Columbia Middle School \\ Shelia Cumiskey, \\ Tyrrell Elementary School
}

In rural eastern North Carolina, the rapid growth of English Learners (ELs) unintentionally makes mainstream classrooms sheltered instruction classrooms. Sheltered instruction is content-based instruction (CBI) where ELs acquire language while learning content. In addition to ELs, this region has a high number of Standard English Learners (SELs). SELs are native English speakers whose dialects are nonstandard and whose home languages differ structurally from academic English. A yearlong professional development used sheltered instruction to focus on academic language proficiency. A local university, two principals and 14 teachers partnered and participated in this weekly professional development. Data were analyzed using Guskey's (2000) framework for evaluating professional development. Findings indicated that when sheltered instruction was implemented with fidelity, teachers' perception of the principal changed from a manager to an instructional leader, content teachers became teacher leaders, instruction focused on academic language proficiency; and there was evidence of academic growth for low achieveing students.

Key Words: Principal professional development, academic language proficiency, school-university partnership, sheltered instruction, instructional leaders.

Over the past decade, the United States has seen a large increase in English Learners (ELs) entering the public school system. From the 1997-98 academic years to the 2008-09 academic years, the overall student population in the nation increased by only 7.22\%; however, the population of ELs increased by $51.01 \%$ (National Clearinghouse of English Language Acquisition (NCELA, 2009). The increase of ELs in the U.S. has not been uniform across states. While some states have not experienced much growth in the EL population, in several states, such as Texas, California, and Florida, it has increased dramatically. In North Carolina this large increase has greatly impacted rural areas. From the 1994-95 academic years to the 2004-05 academic years, the overall student population in the state increased by only $1.1 \%$; however, the population of ELs grew by $371 \%$ (NCELA, 2006). The statistics for the 2009-2010 academic year provided by the North Carolina Department of Public Instruction showed a total of 111,925 ELs. Language instruction programs vary greatly in each and every school system; nevertheless, the EL population in some rural North Carolina schools has increased to a point where some mainstream classrooms have a majority of ELs.
Therefore, mainstream teachers not only teach their curriculum, but also need to incorporate strategies for ELs to allow access to the curriculum due to limited language proficiency. This need to educate in a differentiated manner presents school leaders with a challenge for which principals are not typically prepared.

In addition to ELs, eastern North Carolina has a high number of Standard English Learners (SELs). SELs are native English speakers whose dialects are nonstandard and whose home languages differ structurally from standard academic English. Many SELs live in poverty and, in addition, lack appropriate background knowledge for school settings (Freeman \& Freeman, 2009). The lack of background knowledge creates a deficiency of academic vocabulary, limiting full access to the curriculum (Marzano, 2004). This limitation hinders learning new content that may rely on prior knowledge and experience. Students from these rural areas, students from poverty, and students from low literacy families do not have the exposure to print rich environments, nor do their parents provide language rich environments or serve as academic language role models. 
This study took place at schools in In Tyrrell County, NC. The local economy attracts many immigrants to the local fishing and agricultural industries. Many of the families that move to the area lack English language proficiency. Tyrrell County is one of the most economically distressed counties in North Carolina and designated a Tier 1 county by the Department of Commerce. This level of poverty is reflected in the public schools' Title I designation; $80 \%$ of their students receive free and reduced lunch. In addition, due to the high poverty levels, the level of education in the community is extremely low. The Tyrell County school district is one of the smallest in the state with only one elementary, middle and high school. Due to its small size and its rural location, this school district receives limited per student resources.

The school system is the largest employer in the county employing the majority of college graduates for Tyrrell County. Most children come from homes with low literacy rates and enter schools with limited vocabulary and academic exposure. Approximately $14 \%$ of the student population is Hispanic and the remainder of the population is equally divided between African American and Whites. There is an increasing trend in EL growth in particular, students from Hispanic and Vietnamese backgrounds. During the year of the study, 2010-2011, pre-kindergarten EL enrollment alone grew from $30 \%$ to $50 \%$. This diverse student population comprised of a large number of regional non-standard dialects in addition to the number of non-native speakers. As there is only one ESL teacher for three schools, all teachers in the school system were by necessity both mainstream and ESL teachers. Principals were faced with a challenge that they had not learned in their principal preparation programs, namely how to facilitate professional development for working with SELs that yields academic success.

\section{Context}

This paper describes a yearlong professional development grant, Project CEO, whose purpose was to change the perceived role of the principal from the "booking agent", the one who manages the building, the schedule and the professional development, to the "CEO-Chief Educational Officer", the instructional leader who facilitates, leads and participates in professional development for his/her school with the goal of improving student academic literacy across the content areas.

Project CEO was implemented in a partnership between the local university and two public schools in rural eastern North Carolina. The university partners were two professors, one from the
Department of Educational Leadership and the other from the department of English. Each contributed expertise in effective professional development and coaching, and academic langauge literacy, respectively. The public school partners were the principals and a selected group of teachers from the local elementary school and the local middle school.The researchers delivered professional development to principals and teacher leaders on content-based instructional strategies through implementation of the Sheltered Instruction Observation Protocol (SIOP) Model.

The SIOP model is a research-based model for sheltered instruction. Sheltered instruction is a form of content-based instruction (CBI) in which ELs acquire language while learning content (Chamot \& O’Malley, 1994; Gitomer, Andal, \& Davison, 2005). Teachers of sheltered instruction classrooms typically are content teachers who understand first and second language acquisition and utilize second language teaching strategies to ensure that ELs and SELs learn the English language while fully participating in the grade level curriculum. The SIOP model is a scientific, research-based model that integrates language instruction within content instruction (Echevarria, Vogt, \& Short, 2008). The SIOP model facilitates the teaching of content while simultaneously focusing on academic language development.

Project CEOs professional development focused on improving academic literacy for the students via the SIOP model as well as providing principals and teacher leaders with skills for effective follow-up strategies to ensure implementation of the model. The project addressed two threads of professional development.

\section{Thread 1}

Professional development activities addressed the content of academic language literacy necessary to improve instruction and academic achievement. Research on the need to teach academic language literacy (Freeman \& Freeman, 2009) indicated that many students do not have the specialized skills needed to read and decipher content from textbooks and lectures. Complicating the situation is the limited background knowledge that many students from low socio-economic environments bring to the classroom (Marzano, 2004). In the schools participating in Project CEO, most students enter with limited background experiences, as either SELs or ELs. The professional development focused on a model for content-based instruction (CBI) that has been proven to work with ELLs. The Sheltered Instruction Observation Protocol (SIOP) has been empirically 
tested by Echevarria et al. (2008) and is currently being implemented in districts nationally and in North Carolina in particular. The authors of Project CEO have performed research in rural eastern NC with struggling learners and ELs using the SIOP Model, which resulted in improvements in student achievement (O'Neal, Ringler, \& Lys, 2009; O'Neal, Ringler \& Rodriguez, 2008).

The professional development for Project CEO focused on improving teacher quality by incorporating second language teaching strategies where the second language being taught was "Academic Language". Teachers learned how to build background knowledge; how to focus on the language skills of reading, writing, speaking, and listening in the content areas; how to incorporate higher order thinking skills and learning strategies, and how to create classrooms with high student engagement. Principals learned the content as well as the coaching skills necessary to integrate the knowledge into classroom practice.

\section{Thread 2}

The process for delivering the grant activities was intended to build capacity within the school and promote sustainability over time by changing the principal's role from a building manager who brings in professional development (booking agent) to one of CEO, Chief Education Officer. The principal from each of the two schools served as an instructional leader and provided organizational support and coaching. As CEO, each principal took on the role of a change agent working to create a collaborative culture where teachers encourage and support one another in their efforts to improve instruction and student achievement (Kohm \& Nance, 2009). To that end, the process of implementation of the new knowledge took the form of learning communities where teachers met weekly for instructional dialogue; the time in between meetings included many activities such as peer observations, shared planning time, and creating supplementary teaching materials. This process also helped principals identify and mentor lead teachers as well as promote ongoing teacher growth and development.

\section{Methodology}

A practical participatory evaluation approach (Cousins \&Whitmore, 1999) was utilized in the evaluation of this professional development. In this study, the practical participatory approach engaged university professors, teachers, and principals in ongoing formative evaluation in order to enhance evaluation relevance, ownership, and thus the implementation of the professional development. This evaluation helped to determine the effects of a yearlong professional development project on teaching behaviors of a select group $(\mathrm{N}=13$ teachers and $\mathrm{N}=2$ principals) at Tyrrell Elementary School and Columbia Middle.

Guskey (2000) outlined a five level framework for evaluating professional development:

1. participants' reactions

2. participants' learning

3. organization support and change

4. participants' use of new knowledge and skills

5. student learning outcomes.

Each successive level leads professional development planners and participants closer to the ultimate goal of impacting student learning. Each level also allows the evaluators to collect different pieces of evidence to support the value of the activity to the teacher participant, school community, and student. Utilizing Guskey's (2000) theoretical framework, the researchers employed a variety of metrics to determine results of the ongoing professional development.

Data were evaluated from five levels: the initial workshop; participant knowledge of the SIOP and coaching; organizational support for the professional development; participant implementation; and student outcomes. Quantitative (pre and post-tests) and qualitative data (surveys, interviews, and observations) were collected in each of the levels of professional development from the experimental group.

An initial daylong workshop was held in September, 2010 for project participants to understand the theory and research base of the SIOP model. This initial workshop provided teachers and principals with ample opportunities to practice and receive feedback on their understanding of the SIOP model. The project participants participated in yearlong professional development from October 2010 to June 2011. Activities of the yearlong professional development included: monthly meetings; observation by peers, principals, and researchers; instructional dialogue; ongoing feedback by researchers, principals, and peers.

\section{Results: Evaluation of Professional Development}

Guskey (2000) outlined a five level framework for evaluating professional development: (1) participants' reactions; (2) participants' learning; (3) organization support and change; (4) participants' use of new knowledge and skills; (5) student learning outcomes. 


\section{Participants' Reactions to Initial Professional Development}

The results from this study indicated that the initial SIOP workshop presented a clear and comprehensive picture of the SIOP model of instruction. Participants completed four open-ended questions where they were posed a sentence starter that needed completion. The sentence starters were: "I came expecting..."; "I got..."; "Now I hope..."; and "Now I need to...". Table 1 summarizes the participant responses to the initial SIOP workshop. Table 1 lists the coding system used to describe patterns of responses. For each code, the researchers determined the frequency of comments. Each code description in Table1 also includes a sample response as an illustration of the coding process. According to the data in table 1 , researchers concluded that the initial presentation resulted in $100 \%$ of the teachers and principals indicating their intent to implement the model at their schools and in their classrooms.

\section{Participants' Level of Knowledge}

To determine the level of knowledge of the SIOP model all participants completed a SIOP selfassessment prior to the initial professional development and all indicated limited to no knowledge of the SIOP model. Participants completed the self-assessment again in June 2011 and most participants indicated the use of the SIOP on a daily basis. The SIOP self-assessment inventory was developed and tested by the developers of the SIOP Model (Echavarria, Vogt, \& Short, 2008).

The instrument addresses the eight elements of the SIOP model, asking participants to rate their implementation on a scale from never (0) to occasionally (1) to daily (2). Average scores for each Project CEO participant, pre and post project, are presented in the Table 2 below. Using the SIOP Selfassessment as an indicator of level of knowledge and implementation with fidelity, Table 2 illustrates the pretest and posttest averages indicated that 11 of 13 participants $(84 \%)$ reported an increase in their SIOP implementation. This increase correlates to an improvement in SIOP implementation from occasional to daily usage.

\section{Participant's Level of Implementation}

In addition to participant self-assessments, the grant researchers conducted monthly observations of each participant. Peer coaching also helped to determine level of implementation.

Researchers' observations. Researchers utilized observation instruments validated by the SIOP model. The SIOP consists of 8 components: Lesson preparation, Building Background, Comprehensible Input, Learning Strategies, Interaction Strategies, Practice/Application, Lesson Delivery, and Review/Assessment. Each component has at least 3 observable features. The researchers utilized the SIOP rating scale that ranks each feature within a SIOP component on a scale from 0 (no evidence of implementation) to 4 (full implementation of the indicator). Both researchers conducted a sampling of observations and compared results in order to maximize inter-rater reliability. The observations targeted individual components of the SIOP month by month. By focusing on parts of the SIOP the researchers were able to gather specific data on the use of the SIOP component as well as provide detailed feedback to teachers and principals on the level of implementation. Initially, teachers were not comfortable with the feedback and took the feedback personally. One teacher said, I already do many of these strategies and now you are telling me I need to do more! Another teacher said in a defensive tone, $I$ know my subject and I guarantee I am teaching the content well. Teachers initially also complained to their principals about all the work they were being asked to do. The principals and the university professors collaborated to intensify constructive feedback and to address the concerns raised about time and resources - thanks to the available funding included in the grant. As they continued to have professional dialogue with the researchers the observations and feedback sessions became invaluable to the implementation of the model. By the end of the 8-month period all teachers were implementing the SIOP model with fidelity. Table 3 illustrates the contact hours per teacher throughout the year and the resulting level of implementation. 
Table 1

Participants' Reactions to the Initial Workshop

\begin{tabular}{|c|c|c|c|}
\hline $\begin{array}{l}\text { Sentence } \\
\text { starters }\end{array}$ & Code Description & Occurrences & Sample Data \\
\hline \multirow[t]{3}{*}{ I got... } & $\begin{array}{l}\text { Understanding of the SIOP } \\
\text { Model and teaching } \\
\text { strategies within the model }\end{array}$ & 13 & $\begin{array}{l}\text { "A better understanding about the purpose } \\
\text { of the SIOP and how this will improve my } \\
\text { teaching."; Specific SIOP strategies"; } \\
\text { Increasing understanding of morphology"; } \\
\text { understanding comprehensible input" }\end{array}$ \\
\hline & $\begin{array}{l}\text { Understanding about } \\
\text { language acquisition }\end{array}$ & 5 & $\begin{array}{l}\text { "How it (the SIOP) is beneficial to SELs } \\
\text { as well as ELLs"; "Many strategies and } \\
\text { many ways to implement them with ELL } \\
\text { students"; "How it feels like to work in a } \\
\text { student's shoes who are non-English } \\
\text { speaking students" }\end{array}$ \\
\hline & $\begin{array}{l}\text { Workshop presentation } \\
\text { comments }\end{array}$ & 2 & $\begin{array}{l}\text { "A great day, fast-paced, active } \\
\text { participation"; "A written list of meeting } \\
\text { dates and assignment expectations" }\end{array}$ \\
\hline \multirow[t]{3}{*}{ Now I hope... } & $\begin{array}{l}\text { Positive plans to } \\
\text { implement }\end{array}$ & 10 & $\begin{array}{l}\text { "I hope to implement these strategies in } \\
\text { the classroom"; "Become a better teacher } \\
\text { and reach all students more effectively"; } \\
\text { "to use all activities at some point } \\
\text { throughout the year" }\end{array}$ \\
\hline & Become a teacher leader & 2 & $\begin{array}{l}\text { "I hope I become an effective SIOP } \\
\text { teacher and leader"; "to learn how to help } \\
\text { my teachers help students learn" }\end{array}$ \\
\hline & $\begin{array}{l}\text { Organizational and } \\
\text { implementation challenges }\end{array}$ & 4 & $\begin{array}{l}\text { "I hope I don't get stressed out"; "Be } \\
\text { organized"; allow sufficient time to } \\
\text { complete everything"; I hope teachers } \\
\text { accept this challenge and see the benefits" }\end{array}$ \\
\hline \multirow[t]{2}{*}{$\begin{array}{l}\text { Now I need to } \\
\ldots\end{array}$} & $\begin{array}{l}\text { Spend time planning for } \\
\text { implementation }\end{array}$ & 12 & $\begin{array}{l}\text { "get organized"; prepare myself using } \\
\text { books provided"; "apply strategies in } \\
\text { classroom"; talk more with my partners } \\
\text { about the SIOP" }\end{array}$ \\
\hline & Other comments & 2 & "get some rest"; "clone myself" \\
\hline
\end{tabular}


Table 2

SIOP Self-assessment Scored by Participant

\begin{tabular}{lccc}
\hline Participant & Pretest Average & Posttest Average & Gain/Loss \\
\hline CEO1 & 1.60 & 1.73 & 0.13 \\
CEO2 & 1.60 & 1.30 & -0.30 \\
CEO3 & 1.80 & 1.83 & 0.03 \\
CEO4 & 1.20 & 1.80 & 0.60 \\
CEO5 & 1.17 & 1.93 & 0.77 \\
CEO6 & 1.30 & 1.80 & 0.50 \\
CEO7 & 1.17 & 1.67 & 0.50 \\
CEO8 & 0.93 & 1.87 & 0.93 \\
CEO9 & 1.30 & 1.80 & 0.50 \\
CEO10 & 1.20 & 1.47 & 0.27 \\
CEO11 & 1.73 & -0.10 \\
CEO12 & 1.83 & 1.87 & 0.23 \\
CEO13 & 1.63 & 1.57 & 0.30 \\
\hline
\end{tabular}

Table 3

Level of Implementation

$\begin{array}{ccccc}\begin{array}{c}\text { Participant/ } \\ \text { grade level }\end{array} & \begin{array}{c}\text { Contact } \\ \text { Hours }\end{array} & \begin{array}{c}\text { Level of Implementation } \\ \text { o lowest to 4 highest } \\ \text { Tyrrell Elementary School }\end{array} & \begin{array}{c}\text { Students per } \\ \text { teacher }\end{array} & \begin{array}{c}\text { Students per } \\ \text { administrator }\end{array} \\ \text { Principal } & 42 & & & 280 \\ \text { Teacher: K } & 36.5 & 4 & 17 & 14 \\ \text { Teacher: } 1 & 36.5 & 4 & 17 & 13 \\ \text { Teacher: } 2 & 36.5 & 4 & 19 & \\ \text { Teacher: } 3 & 36.5 & 4 & 22 & \\ \text { Teacher: } 4 & 39.5 & 4 & 3 & \end{array}$

Columbia Middle School

$\begin{array}{cccc}\text { Principal } & 42 & \text { Principal } & \\ \text { Math: 6th } & 39.5 & 4 & 52 \\ \text { English: 6th } & 36.5 & 3 & 52 \\ \text { Science: 6th } & 39.5 & 4 & 52 \\ \text { Math: 7/8 } & 39.5 & 4 & 82 \\ \text { Science: } 7 / 8 & 40.5 & 4 & 82 \\ \text { Social St: } 7 / 8 & 39.5 & 4 & 82 \\ \text { English: } 8 & 39.5 & 4 & 82 \\ \text { Exceptional } & 32.5 & 3 & \end{array}$

Peer coaching. Monthly peer coaching consisted of a clinical observation in which one peer was observed and the other provided feedback on a SIOP component. Hence, one teacher was the observee and the other was observed. These roles switched the next month from one that was being observed to one that was observing, allowing each teacher to experience coaching as the coach and as the one being coached. Data were collected in the form of a monthly written coaching reflection in which participants responded to three questions:

1. During this month's collaborative planning meeting how did you help your partner prepare for this month's SIOP component?" 
2. How did you provide comprehensible feedback? Please give examples and discuss any problems that may have arisen.

3. Based on your coaching sessions and meetings, what do you take away that will help you better coach this component of the SIOP?

Data were collected for 4 months (October, November, December, and February). In analyzing the responses several patterns of responses occurred. Ninety percent of teachers that communicated with their peer about using content based instruction strategies from the SIOP. One teacher commented that, it was very helpful to discuss and throw ideas back and forth until I found a strategy I thought would work for me. Another teacher commented, I did not realize that I also spoke in non-academic language more frequently than I thought; the SIOP has helped me stop and think more about speaking Academic Language when teaching. Participants also commented about better understanding the components of the SIOP model thanks to peer discussions.

I look forward to meeting with my partner because I realize that we are both teaching same concepts at different levels (elementary and middle school) and therefore the SIOP components help us plan

for strategies that they will use in later grade levels.

Regarding offering and receiving creative teaching strategies, one teacher observed she was now more aware of the number of strategies that she could use and also that she was now more open to trying new ideas. Another teacher noted that observations helped her know what to look for when trying to determine what students learned from a lesson. Concerning adapting instruction for those students with different backgrounds, one teacher stated previously she assumed students had similar background knowledge; I now stop to check understanding more often because academic language can confuse students.

The time needed for pre conferencing, observing, and post conferencing among peers was a challenge throughout the year. Peers were matched in pairs, one from an elementary school and another from the middle school. Class schedules made the meeting times difficult because the middle school teachers had common planning period everyday but the elementary school ran a six-day schedule which allotted each teacher a large planning time only once every six days. This planning time was essential for a week's worth of lesson planning. The grant provided money to pay for substitutes; however, teachers preferred not to interrupt their teaching time. As the year progressed many strategies were implemented to find time: for example, stipends paid for work completed after work hours twice a month or stipends paid for working a full day on a Saturday. In the end, teachers collaboratively made their own decisions about meeting times and dates that best fit their schedules. Teachers communicated with their principals to discuss their needs so that the principal could facilitate hiring a substitute or processing stipends.

\section{Discussion}

The discussion of the study results is organized by three themes: the impact of the principals' support, the impact on teacher practice, and the impact on student outcomes. These three themes are the remaining three levels of evaluation in Guskey's model (2000).

\section{Impact of the Principal Support}

All teachers in this study indicated that the level of their principal's support was essential to full implementation of the SIOP model in their classrooms. In analyzing interview and survey data the following principal leadership practices were viewed as valuable to teachers.

Principal's feedback about teachers' practice. Teachers valued their principal's suggestions and feedback on instruction. The feedback was mostly provided during observation post conferences in the form of additional strategies or additional research articles that may enhance the lesson delivery and learning outcomes. The dialogue protocol between these teachers and their principals were that of two professionals discussing teaching and learning for the purpose of improving instruction. Ongoing and continuous feedback is a valuable tool in the professional development because teachers engage in collegial planning and thinking together of the impact of their teaching on students' learning (Joyce \& Showers, 1996). Feedback became a valuable tool to become better teachers and to deliver more effective lessons. As a result of ongoing instructional conversations, teachers collaborated often with their peers and their administrators to seek advice and ideas on how to better implement the SIOP model. As the year progressed the instructional conversation became synergistic and all teachers involved were actively engaged in reflection about practice.

Creative ways to find time. Time was the second most important factor that teachers mentioned as essential in the successful implementation of this professional development. When teachers attend professional development it is important to allow time to practice and apply the new content. The highest indicator present among teachers who implement an innovation is the ability for "teachers to meet regularly to develop lesson plans, examine student work, 
monitor student progress, and assess the effectiveness of instruction, and identify the needs for professional development" (Murphy \& Lick, 2005, p. 55). Because their days were focused on lesson planning and lesson delivery, one very important role of the principal was to find time in the school day for teachers to have instructional conversation, plan, and reflect on their practice. The onus was on the teachers to communicate with the principal about their needs for time. Principals found creative ways to find time such as stipends for time after hours, rearranging daily schedules to allow more time in a subject while teachers planned, allow for a day of planning while the principal covered and taught part of the school day. Teachers valued the principal's understanding that time was needed and therefore utilized their newly found time effectively.

\section{Principals engage in the professional} development. Another major leadership practice that was noticed and mentioned by teachers was that the principals were present and active participants in every training session that teachers attended. For teachers, it was important that by attending the workshops principals understood the content of the professional development and what it should look like in the classroom. More importantly, it was important for the teachers to know that principals understood the time requirements that went with the implementation. The message that teachers received from their principals was that this training is important and any help I am going to give needs to be based on a thorough understanding of what is being learned. A principal's understanding of professional development is essential in leading teachers in the implementation of innovation and facilitating school change and improved student learning (Lindstrom \& Speck, 2004). Teachers saw their principals as learners and felt they were learning together. This also helped teachers and principals make better decisions on what materials and supplies to purchase because each item was closely tied to the instructional conversations between teachers and principals.

The concept of principals being the "booking agent" where they "book" the professional development act, set it up, and walk out of the training once it was underway was dismissed in this yearlong professional development to lead the way for the principal as the "Chief Education Officer, (CEO)". Professional development is essential for teachers to become better teachers and ongoing instructional conversations are key to implementing professional development in classrooms. The CEO's role in implementation is to facilitate the ongoing practice and application process in the classroom (Lindstrom \& Speck, 2004). To facilitate this process, principals must see themselves as learners alongside their teachers. Learners read, apply, reflect, collaborate with peers, seek feedback, and give feedback. Teachers as learners do this in their classrooms and collaborate with their peers with the expectations to become better teachers and improve student-learning outcomes. Principals experience the same, reading, applying, reflecting, collaborating with peers, seeking and giving feedback, however; their classroom is the school building. The principals' students are their teachers and every interaction between teachers and principals that revolved around instruction led to the CEO's goal to improve instruction that impacts student learning.

\section{Impact on Teachers' Practice}

Teacher leaders. As the school year progressed the teachers in the project became teacher leaders of the model. The monthly coaching with the university professors continued; however, a team of teachers now led the whole-group monthly meetings. In jobembedded professional development teachers take responsibility of their learning and that of their colleagues (Sparks, \& Hirsh, 1997). In their school buildings non-participating teachers saw and heard so many great things in the SIOP classrooms that they asked to observe lessons. After peer observations, crucial conversations were held to discuss what they saw and why they implemented the strategies that they did. District level administrators would send state visitors and teacher interns to observe these model classrooms as well. Students in these classrooms were able to explain to the observers what they were learning and why the strategies their teachers used were so helpful. The principals also provided reading materials and strategies to those teachers interested and then met with these teachers to dialogue about the model and its benefits. Overall, the teachers in this project were the catalysts of change by example.

The peer coaching resulted in teachers becoming leaders in their profession. As an example, six teachers at the middle school developed a digital story to describe the SIOP and its impact on their teaching and their students' learning. This digital story was presented at a school board meeting and received excellent reviews. What was significant was that all teachers contributed to telling the story with pictures, quotes, and time to compose the story.

Another leadership opportunity presented itself when four teachers from the project attended a national conference with the university professors. During this conference the professors coached the teachers on the first night on how to write a meaningful reflection about that day's sessions to be shared via email with their colleagues at home. By the second day of the conference the four teachers had devised another creative method to reflect and to engage their 
colleagues at home with an online challenge question. Finally, this group of teachers read many articles relevant to their professional development and even teleconferenced with the authors of one of the books read as a group.

The follow up activities that make coaching a key component of sustainability for any professional development must be job embedded, consistent, and meaningful (Joyce \& Showers, 1996). As the yearlong project ended, principals were already planning for the newly developed teacher leaders to take the lead in writing the professional development activities for the coming year. The entire faculty of the elementary and middle school underwent peers' training. These new teacher leaders also contributed in a planning meeting with the purpose of implementing the SIOP at the high school. Teacher leaders at this meeting took the lead role in justifying and summarizing the necessary activities for an effective yearlong professional development. It was at this precise moment that the teacher leaders confidently assumed the role of coaches. They made a passionate plea to the high school teachers to embrace the SIOP to keep the continuity of student-centered learning and engagement. This small rural district became a primary example of coaching resulting in the creation of teacher leaders.

\section{Impact on Student Learning Outcomes}

In review of student predicted growth targets as indicated by North Carolina's accountability model, the students predicted to score below proficiency on state exams demonstrated the most growth when compared to the previous school year. For example, 14 students in $8^{\text {th }}$ grade math were deemed at risk of not showing growth or proficiency on the state assessment. At the end of the first year of implementation of the project, $57 \%$ of these students surpassed state growth expectations. Beating the predicted odds of not meeting learning growth was a major accomplishment.

In addition, teachers noted that students were retaining more of the content as observed by the increase in quarterly assessments of teacher made tests. Teachers attributed this increase to their lesson planning and delivery. Daily lessons included activities that required students to meaningfully engage in group learning with the expectation that the content learning would be processed by speaking, listening, reading, and writing academic language. Teachers also noted that students were engaging in learning and looking forward to the "fun" activities for the day.

\section{Bottom Line: The Principal and the Process}

This yearlong professional development was developed as a result of several years of experiences with long-term professional development on the topic of academic language proficiency, ELs, and SELs. This yearlong professional development was successful in changing the perceived role of the principal from booking agent to CEO, the role of teachers to teacher leaders, and change in classroom instruction that focused on academic language proficiency. A year is not long enough to make a complete change. Learning the SIOP model takes 3 to 5 years (Echevarria et al., 2008). Lessons learned from this year planted a seed that was continued the second year at both schools. Researchers learned that the next step in improving student achievement was to increase the expectations for writing in academic language. The researchers have since revised the professional development to include more strategies that focus on writing strategies.

With the past five years of professional development on the SIOP (originally researched with ELs) and researching the effects on instruction of teachers of SELs, it is possible to say that a model that focuses on language acquisition strategies is effective in increasing academic language proficiency as long as the professional development is research-based and the process of implementation is strongly supported by an engaged principal (Lindstrom \& Speck, 2004). An engaged principal facilitates ongoing, we recommend weekly, activities that included peer observations, comprehensible feedback, instructional conversations, collaborative planning, celebrations of successes, and ongoing learning from research. This is a big job for a principal in addition to the daily duties and responsibilities. Therefore, the second recommendation the researchers make is for principals to seek and engage partners in this process. In our experience, working with faculty at a local university has proven successful. The work must be collaborative forming a true partnership in learning for all professionals. For rural schools, such as the two in this study, access to resources and expertise was a challenge because of the remote locations of the schools. The state's Department of Education is over four hours away, the closest university is two hours away and, therefore, attendance at frequent and ongoing professional development is a challenge. Teachers in rural schools often attend training for a day and then are left to their own devices to try to implement at their school sites. Principals of rural schools have an important role as teacher developers. Principals need to learn how to develop their teachers because traditional principal preparation programs focus on management and leadership of school 
functions as opposed to adult learning and teacher development. A school-university partnership benefits the faculty in that their practice and research remain current and they learn about applications of theory in rural settings. School-university partnerships are a win-win relationships. In this case, the university faculty, school principals, and teachers continue their professional relationship long after the grant funding ended. There is collegial dialogue often with the help of Skype, email, and texting. The university faculty continues to find ways to provide resources in these rural schools in the form of doctoral student dissertations, master level research, recent research and the school teachers and principals continue to share their teaching successes and inquire into more in-depth teacher development topics related to academic language instruction

\section{References}

Chamot, A., \& O'Malley, J. (1994). The CALLA handbook: Implementing the cognitive academic language learning approach. Reading, MA. Addison-Wesley.

Cousins, J.B., \& Whitmore, E. (1998). Framing participatory evaluation. In E. Whitmore (Ed.), Understanding and practicing participatory evaluation. New Directions for evaluation (pp.523). San Francisco: Jossey Bass.

Echevarria, J., Vogt, M., \& Short, D. (2008). Making content comprehensible for English learners: The SIOP Model. Boston: Pearson.

Freeman, Y.S., \& Freeman, D.E. (2009). Academic language for English language learners and struggling readers. Portsmouth, NH: Heineman.

Gitomer, D. H., Andal, J., \& Davison, D. (2005). Using data to understand the academic performance of English language learners. Policy Issues, 21, 1-17.

Guskey, T. R. (2000). Evaluating professional development. Thousand Oaks, CA: Corwin Press.

Hord, S. M., Rutherford, W.L., Huling-Austin, L., \& Hall, G.E. (2006). Taking charge of change. Austin, TX: Southwest Educational Development Laboratory.

Joyce, B. \& Showers, B. (1996). The evolution of peer coaching. Educational Leadership, 53(6), 12-16.

Kohm, B., \& Nance, B. (2009). Creating collaborative cultures, Educational Leadership, 67(2), 67-72.

Lindstrom , P.H., \& Speck, M. (2004). The principal as professional development leader. Thousand Oaks, CA: Corwin Press.
Marzano, R. J. (2004). Building background knowledge for academic achievement. Alexandria, VA: Association for Supervision and Curriculum Development.

Murphy, C.U., \& Lick, D.W. (2005). Whole-faculty student groups: Creating professional learning communities that target student learning ( $3^{\text {rd }} \mathrm{ed}$.). Thousand Oaks, CA: Corwin Press.

National Clearinghouse of English Language Acquisition. (2009). The growing numbers of English learner students. Retrieved from http://www.ncela.gwu.edu/files/uploads/9/growin gLEP_0809.pdf

National Clearinghouse of English Language Acquisition. (2006). The growing number of limited English proficient students: North Carolina rate of growth. Retrieved from http://www.ncela.gwu.edu/policy/states/reports/st atedata/2004LEP/GrowingLEP 0405 Nov06.pdf

O’Neal, D. Ringler, M. C., \& Rodriguez, D. (2008). Teachers' perceptions of their preparation for teaching linguistically and culturally diverse learners in rural eastern North Carolina. Rural Educator,30(1), 5-13.

O'Neal, D., Ringler, M. C., \& Lys, D. B. (Fall 2009). From skeptics to partners: A university-school partnership, Journal of Staff Development, 30(4), 52-55.

Sparks, D., \& Hirsh, S. (1997). A new vision for staff development. Alexandria, VA: Association for Supervision and Curriculum Development.

\section{About the Authors:}

Marjorie Ringler is an Associate Professor in the Department of Educational Leadership, College of Education at East Carolina University.

Debra O'Neal is a Linguist and Instructor in the Department of English, College of Arts and Sciences at East Carolina University.

Jana Rawls is the principal of Columbia Middle School in Tyrrell County located in eastern North Carolina. Sheila Cumiskey was the principal of Tyrrell Elementary School during the time of the study and currently is the Curriculum/Instruction and Accountability Director for Tyrrell County School District. 